International Journal of Engineering \& Technology, $7(2.29)(2018) 1-3$
International Journal of Engineering \& Technology
SPC
Website: www.sciencepubco.com/index.php/IJET
Research paper

\title{
Circularly polarize antenna array for electromagnetic energy harvesting
}

\author{
Chia Chao Kang ${ }^{1 *}$, Chia Yang Kang ${ }^{2}$ \\ ${ }^{1}$ Universiti Kuala Lumpur (MITEC), Jalan Persiaran Sinaran Ilmu, Bandar Seri Alam, 81750 Masai, Johor \\ ${ }^{2}$ Politeknik Mukah Sarawak, 94600 Mukah, Sarawak \\ *Corresponding author E-mail: wyattkang@yahoo.com.hk
}

\begin{abstract}
Electromagnetic energy harvesting from ambient sources have been presented more than 50 years. In this paper, electromagnetic energy harvesting by using circular polarize antenna array is presented. The proposed antenna is having 2 similar size of spiral inductor that feed by microstrip feed line. The gain, momentum visualization were investigated. The circular polarize antenna are fabricated on Roger 4003 substrates. Based on the observations, it is expected that the gain obtained by the antenna array is higher than the single element antenna. The simulation results show that $3.22 \mathrm{dBi}$ gain can be achieved for single spiral antenna whereas the antenna array can achieved as high as $5.14 \mathrm{dBi}$ at frequency $527 \mathrm{MHz}$. The work concluded that investigations of electromagnetic energy harvesting antenna array is successful.
\end{abstract}

Keywords: Circular Polarize; Electromagnetic Energy Harvesting; Antenna Array

\section{Introduction}

In recent years, energy harvesting has drawn a lot of attention from scientist and researcher. There are many types of energy harvesting like environmental vibration, sunlight or wind and geothermal heat. For example, aircraft airframe (1) can be attached by a vibration sources such as piezoelectric transducer to harvest the small strain into electrical energy (2). Besides that, the electromagnetic wave that broadcasted 24 hours from the base station such as TV, mobile station is allowed for scavenged anytime and everywhere (3). This is the reason the electromagnetic energy harvesting has been very attractive. The process of converting this energy to become an electrical power (4) that will useful to human is called energy harvesting. It is an alternative method for batteries and usually to power up low power sensor modes.

\section{Literature Review}

The important characteristics of an ideal spiral antenna when considering for the performance of electromagnetic energy harvesting was lighter weight, physical size of antenna, inexpensive to manufacture. Besides that, the feeding point is very important because it can attach easily to the input of a spiral antenna with the rest part of the harvesting circuit. Due to the reason, antenna fabrication especially on printed circuit board become the main consideration and increasing in popularity compared to old type of helical antenna and loop wire antenna. This is because the standard electronic consumer device can be easily integrated with the patch antenna to be applied in the wireless application.

In RF integrated circuits, planar inductors usually become one of the important element use to store energy in the form of magnetic fields (5). Others than that, planar spiral inductor also can be fab- ricated on metal layers. In research, there are many different types of shape and geometries coil, all this different type will be used in different wireless applications. For example, toroidal coil used in high inductance discrete components but solenoid coil usually used for radio receiver antenna applications or electromagnet. In order to develop RF electromagnetic energy harvesting system, a circular polarize planar spiral inductor is taking into consideration. The reason is it was widely used in printed circuit board (PCB) applications nowadays. Besides that, the geometry of the spiral antenna have different type of shape (6) such as octagonal (7), star spiral (8) or square spiral (9) and it is easily to integrated in the circuit board design. Figure 1 shows the basic shape of a spiral planar inductor.

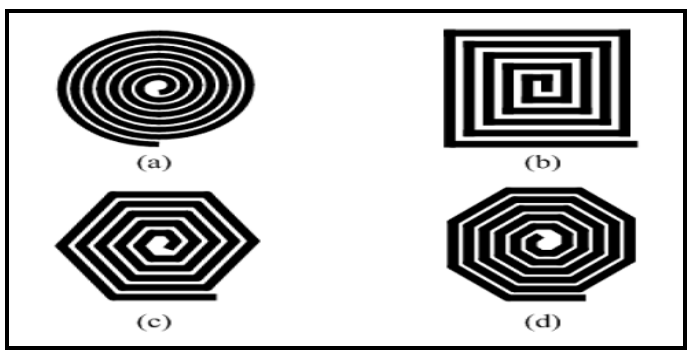

Fig.1: General Shape of Spiral Inductor

\section{Methodology}

This section focus on designing, simulate and measure of circularly polarize antenna array to harvest electromagnetic energy. To accomplish the design of the antenna array, Agilent ADS is using to simulate momentum visualization and gain of the antenna respectively (10). After that, the fabrication is carry out on Duriod $4003 \mathrm{C}$ printed circuit board that have relatively permittivity of 3.38 , thickness of $0.813 \mathrm{~mm}$ and loss of tangent 0.0027 . Patch 
antenna is chosen for the electromagnetic energy harvesting because the efficiency is much more higher compared to other type of antenna (11). In these designs, the circular polarize spiral inductor are used due to circular shape inductor lack of sharp field discontinuities at 90 degree edge (12). Thus, it will minimize the resistance problem and yield better performance (13). In order to calculate for the resonant frequency of the antenna array, the first step is to determined the inductance parameter which are stated in Eq. 1 below (14).

$$
L=0.03937 \frac{a^{2} n^{2}}{8 a+11 c} \times K_{g}
$$

Where $\mathrm{Kg}$ represent the ground plane,

$$
\begin{aligned}
& a=\frac{D_{o}+D_{i}}{4} \\
& c=\frac{D_{o}-D_{i}}{2}
\end{aligned}
$$

Where Di and D0 is the inner and outer diameter of inductor, $\mathrm{n}$ is number of turns of antenna array. Thus, the resonant frequency the

of the antenna array can be calculated by

$$
F=\frac{1}{2 \pi \sqrt{L C}}
$$

Figure 2 and figure 3 below show the single element antenna and circular polarize antenna array where $s$ is spacing and $w$ is width of the copper track. The input is excited by $50 \mathrm{ohm}$ microstrip feeder and the dimension of line width is $1.89 \mathrm{~mm}$.

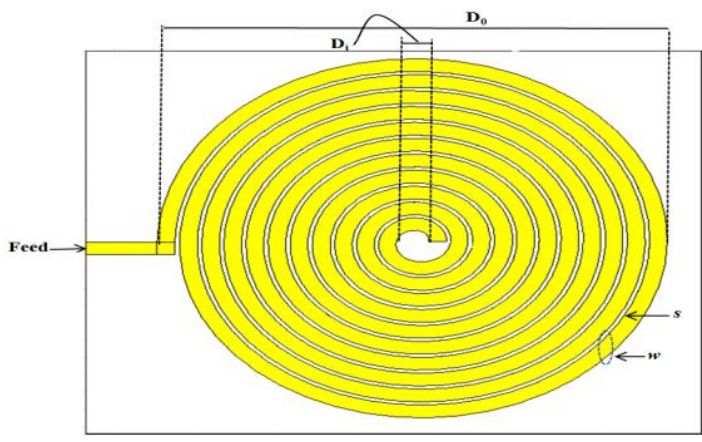

Fig.2: Single Element Antenna

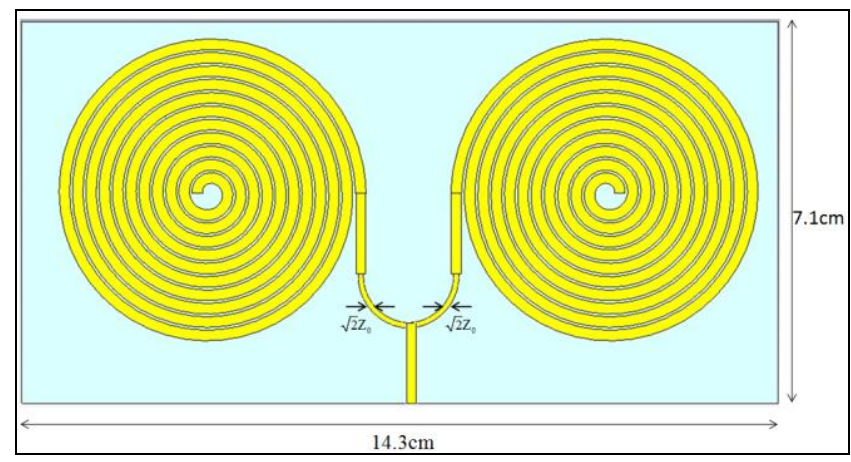

Fig. 3: Circular Polarize Antenna Array

\section{Results and Findings}

The simulated and measurement results are described in this section. Figure 4 show simulated gain of single element antenna and circular polarize antenna array respectively. The frequencies observe range is from $500 \mathrm{MHz}$ to $560 \mathrm{MHz}$. The gain was considered in the direction of the center frequency.

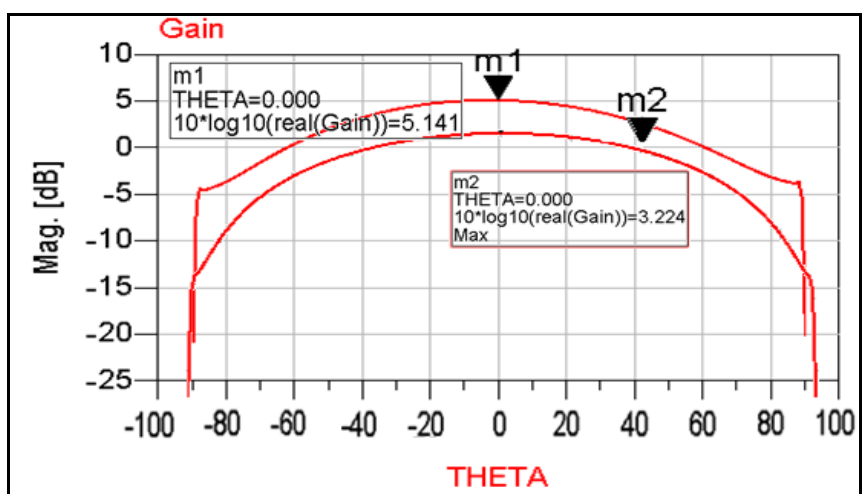

Fig. 4: Gain Plot Single Antenna vs Antenna Array

The gain of the antenna obtained is $5.14 \mathrm{dBi}$ at $527 \mathrm{MHz}$ whereas compare to single circular polarize antenna which was only $3.22 \mathrm{dBi}$. The results obtained show that there is an increasing in gain with antenna array harvesting by using circular polarize type antenna. This is due to the spiral polarize antenna type will received the incoming electromagnetic signal from different direction. Figure 5 below represent electric current visualization of the antenna array.

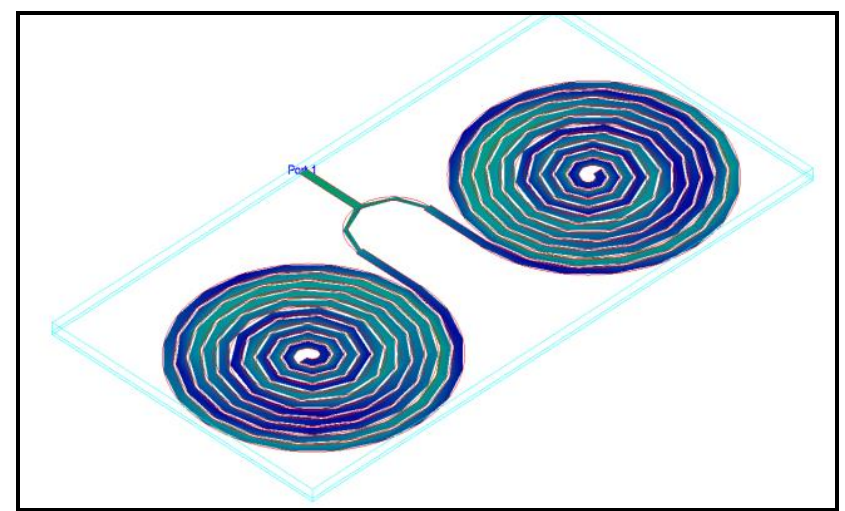

Fig. 5: Momentum Visualization of Antenna Array

The blue colour indicate the original colour and green colour indicate electric current. When the electric current is flowing to one direction through the copper trace, it will produce electromagnetic field that will be use to transmit. The electromagnetic field across the circular spiral inductor that generated by current will determine the inductance. When the gain is increased, the energy harvesting will be enhanced.

\section{Conclusion}

An experimental had presented the study of circular polarize antenna array for electromagnetic energy harvesting. The performance of the antenna array was observed using Agilent ADS and momentum visualization. A detail discussion regarding the circuit parameter value and design frequency were extracted and analyzed. The antenna array has been fabricated and good performance of gain value was obtained compared to single spiral antenna. Thus, it is expected that the proposed antenna structure available for low power consumption application. The proposed circularly polarize antenna array having simple geometry design, cost effective and easy to fabricate. 


\section{Acknowledgement}

This research work is supported by Universiti Kuala Lumpur (MITEC)

\section{References}

[1] Shipley A. Thermal electrical power generation for aircraft. Google Patents; 2013

[2] Pozzi M, Canziani A, Durazo-Cardenas I, Zhu M, editors. Experimental characterisation of macro fibre composites and monolithic piezoelectric transducers for strain energy harvesting. SPIE Smart Structures and Materials+ Nondestructive Evaluation and Health Monitoring; 2012: International Society for Optics and Photonics.

[3] Kamoda H, Hanazawa M, Kitazawa S, Ban H, Kukutsu N, Kobayashi K, editors. Design of rectenna array panel taking into account mutual coupling for RF energy harvesting. Radio and Wireless Symposium (RWS), 2014 IEEE; 2014 19-23 Jan. 2014.

[4] Pirapaharan K, Gunawickrama K, editors. Energy harvesting through the radio frequency wireless power transfer. RF and Microwave Conference (RFM), 2013 IEEE International; 2013 911 Dec. 2013.

[5] Yue CP, Wong SS. Physical modeling of spiral inductors on silicon. Electron Devices, IEEE Transactions on. 2000;47(3):560-8.
[6] Pacurar C, Topa V, Munteanu C, Racasan A, Hebedean C, editors. Spiral inductors inductance computation and layout optimization Electrical and Power Engineering (EPE), 2012 International Conference and Exposition on; 2012: IEEE.

[7] Kilhan K, Changhoon O, Jisoo C, Gunhee H, Ugu Y, editors. Modeling of octagonal spiral inductors for integrated circuit applications. Future of Electron Devices, 2004 International Meeting for; 2004 26-28 July 2004

[8] Mehta A, Mirshekar-Syahkal D, Massey PJ, Nakano H, editors. A switched beam star patch antenna. 2008 IEEE Antennas and Propagation Society International Symposium; 2008 5-11 July 2008.

[9] Phaebua K, Torrungrueng D, Phongcharoenphanich C, editors. Design of planar rectangular spiral antennas for the wireless vehicle battery charging system. 2013 Asia-Pacific Microwave Conference Proceedings (APMC); 2013 5-8 Nov. 2013.

[10] Nath S, Rana S. The Design and Development of Microstrip Patch Antenna using simulation studies by ADS. IJESS

[11] Gowda VR. A Planar And Integrated Rectenna For Wireless Power Reception. 2011.

[12] Pieters P, Vaesen K, Diels W, Carchon G, Brebels S, De Raedt W, et al., editors. High-Q integrated spiral inductors for high performance wireless front-end systems. Radio and Wireless Conference, 2000 RAWCON 20002000 IEEE; 2000: IEEE.

[13] Chen J, Liou JJ. On-chip spiral inductors for RF applications: an overview. Semiconductor Technology and Science. 2004;4:149-67.

[14] Bahl IJ. Lumped elements for RF and microwave circuits: Artech house; 2003. 